\title{
A Study of Pulmonary Function Tests in Menstrual Females in and around Mullana, Ambala
}

\author{
S. Sharma ${ }^{1}$, Gurdev Goyal ${ }^{2}$, Anjana Mittal $^{3}$, L. Walia ${ }^{4}$, Amit Mittal $^{5}$
}

\begin{abstract}
${ }^{1}$ Department of Physiology, M. M. Institute of Medical Sciences and Research, Mullana, Haryana, India. ${ }^{2}$ Department of Physiology, M. M. Institute of Medical Sciences and Research, Mullana, Haryana, India. ${ }^{3}$ Department of Anatomy, M. M. Institute of Medical Sciences and Research, Mullana, Haryana, India. ${ }^{4}$ Department of Physiology M. M. Institute of Medical Sciences and Research, Mullana, Haryana, India. ${ }^{5}$ Department of Radiodiagnosis, M. M. Institute of Medical Sciences and Research, Mullana, Haryana, India.
\end{abstract}

\section{ABSTRACT}

\section{BACKGROUND}

The blazing feature of female reproductive system is the shedding of uterine epithelium at regular intervals with bleeding, termed as menstruation. The dynamic endocrine interplay reflecting rhythmic changes in the rate of secretion of ovarian hormones during different phases of menstrual cycle are known to affect the physiological functioning of various systems of the body which include the reproductive system and the other non-reproductive system. Pulmonary functions show such variations during the different phases of menstrual cycle. So, the present study was carried out to study the pulmonary functions in different phases of menstrual cycle.

\section{METHODS}

This is a descriptive cross-sectional study conducted in the Department of Physiology of Maharishi Markandeshwar Institute of Medical Sciences and Research (MMIMSR), Mullana, Ambala (Haryana). 100 female subjects in their reproductive age having regular menstrual cycles were studied. Pulmonary function parameters were assessed during pre- and post-ovulatory phase of menstrual cycle. All anthropometric parameters such as age, weight in Kgs., Height in cms., were recorded and BMI was calculated. Data was analysed by paired T test to obtain statistical significance ( $\mathrm{p}$ value) between pre-ovulatory and post-ovulatory phases of menstrual cycle.

\section{RESULTS}

Our study shows a highly significant increase in FEV1 parameter during post ovulatory phase having mean values of $2.55 \pm 0.26$ as compared to pre-ovulatory phase with the mean values of $2.22 \pm 0.15$. We found a significant increase in FVC (L), during post ovulatory phase as compared to pre ovulatory phase of menstrual cycle.

\section{CONCLUSIONS}

The results obtained could be attributed to the role of Progesterone acting as a bronchodilator by causing relaxation of smooth muscles lining the bronchial walls resulting an increase in the ventilatory capacity of the individuals. Further the present study may find its clinical application in suggesting the clinicians to supplement progesterone hormone to the females affected with inflammatory lung diseases such as asthma, COPD and cystic fibrosis.

\section{KEY WORDS}

Pulmonary Function Parameters, Menstrual Cycle, Preovulatory Phase
Corresponding Author: Dr. Gurdev Goyal, Department of Physiology, M. M. Institute of Medical Sciences and Research, M. M. Deemed to be University, Mullana, Ambala-133207, Haryana, India. E-mail:drdevgoyal@gmail.com

DOI: $10.14260 /$ jemds/2019/704

Financial or Other Competing Interests: None.

How to Cite This Article:

Sharma S, Goyal G, Mittal A, et al. A study of pulmonary function tests in menstrual females in and around Mullana, Ambala. J. Evolution Med. Dent. Sci. 2019;8(43): 3249-3252, DOI:
Submission 22-08-2019,

Peer Review 05-10-2019,

Acceptance 11-10-2019,

Published 28-10-2019. 


\section{BACKGROUND}

According to Estelle Ramey, the shedding of blood is always associated with injury, disease or death in man. Only the female half of the humanity is seen to have the magical ability to bleed profusely each month and still rise phoenix-like from the gore'. The complex interplay of hormones in females is responsible for the cyclic shedding of the endometrium manifesting as physiologic uterine bleeding called Menstruation. The menstrual cycle is divided into two phases, follicular and luteal, typified by specific hormonal fluctuations and separated by ovulation at midcycle. The follicular phase starts with the first day of menstruation and is followed by the luteal phase from ovulation until menstruation restarts. Fluctuations in many physiological functions occur throughout the different phases of the menstrual cycle due to these rhythmic hormonal changes. Considering this, one cannot help wondering whether the physiological changes due to the menstrual cycle can have a positive or negative impact on pulmonary function parameters. According to most of the studies, the pulmonary functions also had effect on different phases of menstrual cycle. It is suggested that lung functions show changes dependent on the different phases of menstrual cycle. In this research conducted by us, we moderately attempt to detail the physiological changes during the menstrual cycle relevant to the pulmonologist and discuss our research study conducted on these subjects in relation to pulmonary functions with a goal to find out how the phase of the menstrual cycle could alter pulmonary function parameters and whether this could help in one way or other the women becoming more affected with lung diseases like asthma, chronic obstructive pulmonary disease and inflammatory diseases for an unknown reasons in their management and outcomes. It has also been suggested that Sex hormones play a role in mediating the sex differences in asthma, and particularly in the asthma exacerbation that many women experience around the premenstrual period. Menstrualrelated adverse effects on asthma have been recognized since long, but the causes are poorly understood. Studies investigating sex hormone/female sex effects in asthma have evaluated airflow, airway responsiveness, and/or allergicinflammatory parameters over the menstrual cycle. Diffusing capacity has not been evaluated, even though gas transfer varies in healthy women over the menstrual cycle. Various research studies have shown that versatile physiological responses are produced as the level of hormones i.e. progesterone and oestrogen fluctuate in different phases of menstrual cycle. Due to thermogenic effect of progesterone, there is rise in basal body temperature at the time of ovulation of at least $0.2^{\circ} \mathrm{C} .1^{-2}$ It is to be recognized that Progesterone also decreases the alveolar and arterial $\mathrm{pCO}_{2}$ in luteal phase of menstrual cycle and provides strength to smooth muscles by acting as a smooth muscle relaxant. ${ }^{3-4}$ However, it is still uncertain that all these changes of respiratory function parameters indicate their existence during luteal phase of menstrual cycle. Therefore, present study was carried out to observe the changes in pulmonary functions during different phases of menstrual cycle in order to enlighten the health of female.

\section{METHODS}

The descriptive cross-sectional study had been conducted in the Department of Physiology of Maharishi Markandeshwar Institute of Medical sciences and Research (MMIMSR), Mullana, Ambala (Haryana) after the taking ethical approval by the Institutional Ethics Committee of MMIMSR, Mullana. 100 female subjects in their reproductive age having regular menstrual cycle of 21- 35 days duration as established by history for at least 6 months were enrolled as per convenience sampling method. Subjects were enrolled after taking written informed consent. Pulmonary function parameters (FVC, $\mathrm{FEV}_{1}, \mathrm{FVC} / \mathrm{FEV}_{1}$ ) were assessed during preovulatory and post ovulatory phases of menstrual cycle. The equipment used was computerized spirometer Spiro excel (Medicaid systems Chandigarh).

\section{Inclusion and Exclusion Criteria}

The participants were excluded on the basis of history taken from each subject for any respiratory illness or any allergic symptoms in the recent times. Females having history of irregular menstrual cycles, those on hormonal replacement therapy, females using any contraceptive pills, posthysterectomy patients, having history of chronic pulmonary obstructive disease, having any history of cardiovascular disease or having history of smoking, alcohol intake or any psychiatric illness were excluded from the study used.

The different phases of menstrual cycle were estimated as per the menstrual history related questionnaire and date of last menstrual period, as- 1 . menstrual phase- during the 1 2 day of the menstrual bleeding, 2. follicular phase- 3-5 day after complete stoppage of bleeding, 3 . luteal phase- 14 days after the mid follicular phase

All the participants were asked to report thrice in the Respiratory Research Laboratory in the Department of Physiology for pulmonary function test and respiratory efficiency test, according to their phases of menstrual cycle (Once in each phase). The height and weight of each participant were recorded every time, but for reporting only the first-time measurements were considered.

\section{Statistical Analysis}

All anthropometric parameters such as age, weight in Kgs, Height in cms were recorded and BMI was calculated. It was then analysed by SPSS computer program for windows version 20. Mean \pm SD (Standard deviation) was calculated and paired $T$ test was used to obtain statistical significance ( $p$ value) between pre-ovulatory and post-ovulatory phases of menstrual cycle.

\section{RESULTS}

\begin{tabular}{|c|c|}
\hline Parameters & Mean \pm SD \\
\hline Age (Years) & $23.43 \pm 2.20$ \\
\hline Height $(\mathrm{cms})$ & $161.06 \pm 2.88$ \\
\hline Weight $(\mathrm{Kg})$ & $58.23 \pm 6.74$ \\
\hline $\mathrm{BMI}\left(\mathrm{Kg} / \mathrm{m}^{2}\right)$ & $22.43 \pm 2.51$ \\
\hline Table 1. Anthropometric Parameters \\
\hline
\end{tabular}


On analysis of 100 female subjects, the average age (years) was $23.43 \pm 2.20$ (Mean $\pm \mathrm{SD}$ ), average height (cms) was $161.06 \pm 2.88$ (Mean $\pm \mathrm{SD}$ ), average weight $(\mathrm{Kg})$ was $58.23 \pm 6.74$, average BMI was 22.43 \pm 2.51 (Mean \pm SD).

The values obtained for volume of air exhaled during first second of FVC manoeuvre i.e., FEV1 for both study groups with Mean \pm SD in pre-ovulatory $(2.22 \pm 0.15)$ and post ovulatory $(2.56 \pm 0.26)$ with $\mathrm{p} \leq 0.001$ are shown in table no. 2 . Results obtained by our study show a highly significant increase in FEV1 parameter during post ovulatory having mean values of $2.55 \pm 0.26$ phase as compared to pre ovulatory phase with the mean values of $2.22 \pm 0.15$.

\begin{tabular}{|c|c|c|c|}
\hline Sl. No. & Parameters & Pre-0vulatory & Post-0vulatory \\
\hline 1. & $\mathrm{FEV}_{1}(\mathrm{~L} / \mathrm{s})$ & $2.22 \pm 0.15$ & $2.55 \pm 0.26$ \\
\hline 2. & $\mathrm{FVC}(\mathrm{L})$ & $2.41 \pm 0.16$ & $2.84 \pm 0.28$ \\
\hline 3. & $\mathrm{FEV}_{1} / \mathrm{FVC}(\%)$ & $91.66 \pm 3.94$ & $89.87 \pm 5.68$ \\
\hline \multicolumn{4}{|c|}{ Table 2. Mean \pm SD of Pulmonary Function Parameters- } \\
FEV1, FVC and FEV/FVC \\
\hline
\end{tabular}

\section{DISCUSSION}

Menstrual cycle is periodical shedding of epithelium leading to uterine bleeding following an invisible interplay of hormonal levels during the reproductive phase of females. A normal menstrual cycle is characterized by the rhythmic fluctuation in the ovarian hormones-oestrogen and progesterone during different phases of menstrual cycle menstrual, follicular and luteal phases. These cyclic changes in the rate of secretion of ovarian hormones produce corresponding changes not only in the reproductive system but in other organ systems as well. Progesterone increases the ventilatory response of respiratory centre to $\mathrm{CO} 2$ and leads to reduced arterial and alveolar $\mathrm{pCO}_{2}$ in luteal phase. It is also a smooth muscle relaxant and a drop-in plasma levels of progesterone in premenstrual days may result in bronchoconstriction due to the withdrawal of this relaxant effect on bronchial smooth muscle.

The cyclical variations in hormones such as progesterone and oestrogen during each menstrual cycle is associated with certain physiological changes including lung functions parameters also. Anthropometric and pulmonary function parameters (FVC, FEV1, FEV1/FVC) were assessed and correlated in both pre ovulatory and post ovulatory phases of menstrual cycle. The present study showed that various pulmonary function indices show significant variation during different phases of menstrual cycle of women in reproductive age group. In our study we also found decrease in $\mathrm{FEV}_{1} / \mathrm{FVC}$ ratio during postmenstrual phase is due to highly significant increase in FVC as compared to FEV 1 .

Volume of air exhaled during initial second of FVC manoeuvre is regarded as $\mathrm{FEV}_{1}$. Pulmonary function data was collected with for both study group with Mean \pm SD in preovulatory $(2.22 \pm 0.15)$ and post ovulatory $(2.56 \pm 0.26)$ and showed in table no. 2 with $\mathrm{p} \leq 0.001$. Results obtained by our study show a highly significant increase in $\mathrm{FEV}_{1}$ during post ovulatory phase as compared to pre ovulatory phase.

Another study also reported statistically significant increase in FVC due to potentiating of prostaglandin by progesterone which induces relaxation of bronchial smooth muscles ${ }^{4}$. This significant increase in $\mathrm{FEV}_{1}$ is due to action of progesterone on respiratory centers, peripheral and central chemoreceptors which on stimulation influences the cholinergic outflow of airways. The major excitatory input to airway smooth muscles which fire during inspiration have preganglionic cell bodies in ventral respiratory group in region of nucleus ambiguous. .-8 $^{-1}$

FVC was found to be significantly increased in post ovulatory phase of menstrual cycle in our study as compared to pre ovulatory phase. This result is in consensus with other studies and cause found to be increased level of progesterone in luteal phase of menstrual cycle. .-11 $^{-1}$

The increased oxygen consumption may be due to increase in basal metabolic rate due to hyperventilation. ${ }^{12}$ Further the direct stimulation of respiratory centers could be through oestrogen dependent progesterone receptors at hypothalamic site mediated via RNA \& protein synthesis mechanisms. ${ }^{13}$ This phenomenon could be correlated from the observations of Beynon, et al. ${ }^{14}$ Who studied the effects of intramuscular progesterone on patients with asthma. They found that the dosage of bronchodilators was less in patients receiving progesterone. Low levels of progesterone in premenstrual phase may cause relative decrease in the values of lung volumes and capacities.

The differences in FEV1 values in different phases of menstrual cycle i.e. a highly significant increase in FEV1 during the post ovulatory phase as compared to pre ovulatory phase were not supported by the study Changes in peak expiratory flow and respiratory strength during the menstrual cycle done by Da Silva SB et al. ${ }^{15}$ They could not find any significant difference of FEV1 in different phases of menstrual cycle. Dimple Arora et al observed that mean values of all lung functions i.e., FEV1, PEFR, FEF 25-75\% were significantly higher in secretory phase followed by follicular phase and lowest in menstrual phase in asthmatic women and concluded that the most possible cause for this increase is the hyperventilation associated with increased levels of progesterone secretion in this phase. ${ }^{16}$

Increase in alveolar ventilation during pregnancy and luteal phase of menstrual cycle is well known and has been attributed to increased levels of progesterone because progesterone has been shown to have a smooth muscle relaxant effect and therefore may have a bronchodilator action. The reports indicate the influence of progesterone on central (Medullary) and peripheral receptors causing hyperventilation and hypocapnia in the luteal phase of normal menstrual cycle and pregnancy by increasing the sensitivity of the receptors, and this increased sensitivity of respiratory system to progesterone in luteal phase has been attributed to cause a beneficial compensatory mechanisms to meet the increased demands during pregnancy. Foster et al showed progesterone mediated relaxation of the bronchial smooth muscle in animal models through a betaadrenoreceptor mediated mechanism. Exogenous administration of progesterone is often prescribed for hypoventilation syndrome. It is also known to cause relaxation of smooth muscle especially of the reproductive and gastrointestinal system. Keane et al demonstrated reduced spontaneous contraction and decreased magnitude of maximal contraction in human gall bladder exposed to progesterone in vitro. Everson et al have reported relaxation of gall bladder muscle in luteal phase of menstrual cycle. Further due to beneficial role in pre-menstrual asthma, 
wherein the asthmatic attacks are increased when the serum levels of progesterone fall have also been suggested.8,17

Among three phases of menstrual cycle (i.e., menstrual stage, proliferative stage and luteal stage), the enhanced ventilation was observed in the luteal stage might be correlated to the higher progesterone levels Amrith Pakkala et al didn't find any changes in FVC, FEV1 and maximum mid expiratory flow. ${ }^{18}$ Mary Behan et al. said progesterone could also act by altering the release of neuromodulators such as serotonin in brainstem respiratory nuclei. ${ }^{19}$

\section{CONCLUSIONS}

There is significant increase in $\mathrm{FVC}, \mathrm{FEV}_{1}$ during postovulatory phase of menstrual cycle in which the level of progesterone is more. Progesterone acts as a smooth muscle relaxant and relaxes the bronchial smooth muscle. As it is a steroidal hormone, it crosses the blood brain barrier easily and activates the central chemoreceptors of CNS to cause hyperventilation, which further can increase the oxygen consumption. Our attempt to establish the relationship of hormonal level fluctuations during the different phases of menstrual period with the pulmonary function tests could be of help to clinicians to supplement progesterone hormone to the females affected with inflammatory lung diseases such as asthma, COPD etc. There is still dearth of such research which could be improved by adding few more parameters that might help in clinical investigations and treatments.

\section{REFERENCES}

[1] Ganong WF. Ganong's Review of medical Physiology. In: Barrett KE, Barman SM, Boitano S, et al. eds. The Gonads: development and function of the reproductive system. $23^{\text {rd }}$ edn. New York: McGraw-Hill 2010: p. 411.

[2] Keele CA. Samson Wright's applied Physiology. In: Keele CA, Neil E, eds. The menstrual cycle. $13^{\text {th }}$ edn. New York: Oxford University Press 1982: p. 570-1.

[3] Hebbar KR. Comparative study of pulmonary function tests in women in different phases of menstrual cycle with and without contraceptive pills. Journal of Dental and Medical Sciences 2013;8(5):21-5.

[4] Mannan SR, Begum N, Begum S, et al. Relationship of Forced vital capacity (FVC), Forced expiratory volume in first second $\left(\mathrm{FEV}_{1}\right)$ and $\mathrm{FEV}_{1} / \mathrm{FVC}$ with plasma progesterone level during different phases of normal menstrual cycle. Journal of Bangladesh society of Physiologist 2007;2:07-12.

[5] Gavali MY, Gavali YV, Gadkari JV, et al. Influence of menstrual on lung functions in young healthy medical students. International Journal of Healthcare and Biomedical Research 2013;2(1);30-4.
[6] Dabhiowala S, Kathrotia R, Patel D, et al. Pulmonary functions in different phases of menstrual cycle and its relation with serum progesterone levels. National Journal of Indian Research and Medicine 2011;2(4):3942.

[7] Prabha KC, Martin RJ. Role of central neurotransmission and chemoreception on airway control. Respir Physiol Neurobiol 2010;173(3):213-22.

[8] Rajesh CS, Gupta P, Vaney N. Status of pulmonary function tests in adolescent females of Delhi. Indian journal of Physiology \& Pharmacology 2000;44(4):4428.

[9] Nandhini R, Subhashini AS. Variation in the pulmonary functions with the phases of the menstrual cycle in adolescent females. Journal of Clinical and Diagnostic Research 2012;6(2):173-5.

[10] Hebbar KR. Effect of endogenous female hormones on lung functions. Journal of Evolution of Medical and Dental Sciences 2013;2(34):6519-24.

[11] Mishra A, Kamal RB. Variation in pulmonary function tests parameters in different phases of menstrual cycle in healthy female medical students. National Journal of Physiology and Pharmacology 2015;5(5):357-60.

[12] Das TK, Jana H. Basal oxygen consumption during different phases of menstrual cycle. Indian Journal of Medical Research 1991;94:16-9.

[13] Bayliss DA, Millhorn DE. Central neural mechanisms of progesterone action: application to the respiratory system. Journal of Applied Physiology 1992;73(2):393404.

[14] Beynon HL, Garbett ND, Barnes PJ. Severe premenstrual exacerbation of asthma. The effect of intramuscular progesterone. Lancet 1988;2(8607):370-2.

[15] Da Silva SB, De Sousa RVE, De Sousa MB. Changes in peak expiratory flow and respiratory strength during the menstrual cycle. Respir Physiol Neurobiol 2006;150(23):211-9.

[16] Dimple, Sandhu PK, Mehta K, et al. Expiratory flow rate changes during menstrual cycle. Pak J Physiol 2015;11(3);3-5.

[17] Diagnault PG, Fazekas AG, Rosenthal L, et al. Relationship between gallbladder contraction and progesterone receptors in patients with gallstones. American Journal of Surgery 1988;155(1):147-51.

[18] Pakkala A, Bajentri AL, Ganashree CP, et al. Hormonal influence on the adaptability of the pulmonary system to exercise in proliferative phase of menstrual cycle in a group of perimenopausal women. International Medical Journal of Sifa University 2014;1(1):2-4

[19] Behan M, Wenninger JM. Sex steroidal hormones and respiratory control. Respir Physiol Neurobiol 2008;164(1-2):213-21. 